\title{
Diacronie
}

Studi di Storia Contemporanea

$N^{\circ} 7,3 \mid 2011$

«Spagna Anno Zero»: la guerra come soluzione

\section{Política y sociedad en la retaguardia nacional: Valladolid 'capital del Alzamiento' (1936-1939)}

\section{Matteo Tomasoni}

\section{(2) OpenEdition}

\section{Journals}

Edición electrónica

URL: http://journals.openedition.org/diacronie/3209

DOI: 10.4000/diacronie.3209

ISSN: 2038-0925

\section{Editor}

Association culturelle Diacronie

Referencia electrónica

Matteo Tomasoni, « Política y sociedad en la retaguardia nacional: Valladolid 'capital del Alzamiento' (1936-1939) », Diacronie [En línea], № 7, 3 | 2011, documento 4, Puesto en línea el 29 julio 2011 , consultado el 01 mayo 2019. URL : http://journals.openedition.org/diacronie/3209; DOI : 10.4000/ diacronie.3209 


\title{
Diacronie
}

N. 7 | 7|2011 Spagna Anno Zero: la guerra come soluzione

4/

\section{Política y sociedad en la retaguardia nacional: Valladolid 'capital del Alzamiento' (1936-1939)}

\author{
Matteo TOMASONI*
}

Valladolid, histórica y trascendental ciudad de la meseta castellana, protagonizó desde los primeros meses de la Guerra Civil Española un singular experimento de “administración nacional”, convirtiéndose en ejemplo político-institucional para muchas ciudades del bando sublevado. Durante los años del conflicto, a causa de su posición en la retaguardia, acabaría por constituirse en un importante 'feudo' nacional; no sólo como base para la organización bélico-logística, sino también como centro de irradiación doctrinal. Falangistas, militares, cedistas y todo tipo de exponentes de la derecha tradicional concurrieron en la formación de un peculiar pero a la vez funcional conjunto político. Sin embargo no tardarían en manifestarse los primeros enfrentamientos, siendo la clase política local un incuestionable reflejo de la heterogeneidad del Movimiento Nacional. No obstante, durante todo el curso del conflicto (e incluso después de su conclusión) la rigurosa unanimidad del pleno frente a los expedientes y las depuraciones cotidianas acabaría con cualquier residuo de resistencia 'roja', encarrilando la ciudad hacia el «glorioso» porvenir de la Nueva España. 
«La guerra había impuesto una pausa, había hecho sonar una tregua hipócrita en el vivir de la ciudad, y todo se ralentizaba en las tareas diarias, y todo se constituía en una supuesta normalidad que callaba la sangre y los muertos de cada tarde, de cada noche, o las noticias del frente, pero cada día había más mujeres de negro por la calle, más lutos no dichos, más entierros inexplicables»1.

\section{La sublevación en la capital de Castilla la Vieja: lucha callejera y control nacional}

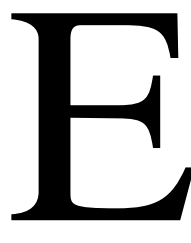

1 golpe de estado del 18 de julio de 1936 movilizó buena parte del ejército, de la Falange y de la milicia sublevada en un intento de acabar rápidamente con el régimen republicano español. Principal propósito de la sublevación fue la ocupación de objetivos claves como los Ayuntamientos y las infraestructuras públicas, además de la difusión de un mensaje insurreccional entre la población civil. No obstante, en muchas capitales el golpe fracasó, siendo sólo en una minoría de éstas - especialmente en las zonas rurales tradicionalmente más conservadoras - donde los nacionales lograron hacerse con el control de las alcaldías ${ }^{2}$.

En aquellas áreas donde por tradición el voto ciudadano solía ser favorable a la derecha conservadora 3 - como podría ser el caso de la provincia de Valladolid - los

1 UMBRAL, Francisco, Capital del dolor, Barcelona, Planeta, 1996, p. 126.

2 Al producirse el golpe «los nacionales lograron hacerse dueños de la situación con facilidad en la España rural y agrícola, como Navarra, Aragón, Galicia, Castilla la Vieja, Islas Canarias, parte de las Baleares y algunos puntos de Andalucía y Extremadura. Mientras que la España más urbanizada e industrial se mantuvo fiel a la República, como fueron los casos de Madrid y Barcelona». Cfr., MÁRQUEZ HIDALGO, Francisco, Las sublevaciones contra la Segunda República, Madrid, Síntesis, 2010, p. 114.

3 Según el análisis que la profesora Marcos del Olmo propone, el mantenimiento de un 'estatus $q u o$ ' dentro de la política castellana representó la continuidad de una región "políticamente caracterizada", en la que «los 'lideres' de otro tiempo se hagan con el control de la situación presente». Estos auténticos "árbitros de la contienda" serían a la vez aquellos que fomentaron el desarrollo de un componente político relevante durante las distintas fases de la etapa republicana; la 'derecha tradicional castellana' compuesta por elementos de la C.E.D.A., del bloque agrario y de los monárquicos abrió el paso a una «nueva derecha [...] digna sucesora del binomio conservadores/liberales». Un conjunto político que por lo tanto no tardaría en ocupar un preciso lugar dentro del panorama político regional, merced a la creciente adhesión en las afiliaciones tras la etapa constituyente. Cfr., MARCOS DEL OLMO, María Concepción, Voluntad popular y urnas. Elecciones en Castilla y León durante la Restauración y la Segunda República (1907-1936), Valladolid, Secretariado de Publicaciones, 1995, pp. 144-168. 
golpistas recibieron cada vez más apoyo, que a lo largo de pocos días se convirtió en su arma para hacerse con el control de los principales centros urbanos. Sin embargo, es importante tener en consideración que en la capital castellana también los grupos socialistas y de la CNT (en su mayoría obreros de los talleres del ferrocarril) se organizaron en milicias anti-golpistas, aunque su intento fue prontamente frustrado a causa del mayor número de efectivos sublevados. Respecto a este asunto hay que tener en cuenta que la lucha entre bandos no era algo nuevo en la ciudad; desde el comienzo de los años Treinta, la germinación de los primeros núcleos del "Jonsismo español” entre ellos recordamos la local Juntas Castellanas de Actuación Hispánica (JCAH) de Onésimo Redondo - alimentó una cierta rivalidad entre defensores de una ideología, la nacionalsindicalista (según algunos entre las primeras manifestaciones de un "fascismo a la española”4) y las masas obreras partidarias del marxismo. Un enfrentamiento que no tardó en convertirse en lucha callejera y armada, que acercó gradualmente al grupo nacionalsindicalista hacia posiciones reaccionarias indispensables para fomentar una insurrección antigubernamental. La política de la Falange vallisoletana se convirtió en una fragmentada serie de provocaciones publicadas a través del periódico Libertad, a pesar de las censuras, hasta su efectiva incorporación en la causa nacional5. En un clima de constante preocupación e incesantes enfrentamientos, donde no faltaron tiroteos y muertos, madurarían rápidamente las condiciones necesarias para favorecer el acto de sublevación antigubernamental. El 17 de julio de 1936 empezó el Alzamiento en el protectorado marroquí, extendiéndose al día siguiente por las principales capitales de la península, incluida Valladolid ${ }^{6}$. Durante los siguientes tres años, la

\footnotetext{
4 Así describirían Falange Española de las JONS, algunos de los más importantes exponentes del partido comunista español: «en 1933 el peligro fascista ya había adquirido en España contornos amenazadores, con el estímulo que le prestaba el triunfo del fascismo alemán. La reacción fascista se agrupó entonces en tres corrientes principales. La primera, filial del fascismo italo-germano, estaba integrada por diversos grupos que constituyeron la Falange Española de las JONS (Juntas de Ofensiva Nacional Sindicalista). Carente de asistencia y de calor popular, Falange reclutó sus escuadras de pistoleros entre elementos desclasados y señoritos ociosos, que aportaban al clima político de nuestro país la "dialéctica de las pistolas" y un odio ciego hacia las ideas de la democracia y del progreso». Cfr. Historia del Partido Comunista de España, París, Éditions Sociales, 1960, p. 81.

5 Los vientos de guerra que en Valladolid empezaron a recorrer las calles mucho antes del Alzamiento, se intensificaron a partir de febrero de 1936 tras las contestadas elecciones generales y la victoria del Frente Popular. Entre los grupos de las ultraderechas se hizo cada día más fuerte la solución armada, según las disposiciones de José Antonio y en Valladolid, de Onésimo Redondo, la cuya implicación en un complot en contra de la República se convertiría en la base del Alzamiento en la ciudad del Pisuerga: «desde marzo, la actividad conspiradora será incesante, abarcando el reparto de propaganda [...], la compras de armas, el entrenamiento de patrullas falangistas». MARTÍN JIMÉNEZ, Ignacio, La Guerra Civil en Valladolid (1936-1939). Amaneceres ensangrentados, Valladolid, Ámbito, 2000, pp. 32-34.

6 «Durante la noche del día 17 de julio, las comunicaciones entre Valladolid y Madrid habían quedado interrumpidas. Con esta medida, se pretendía restar a los sublevados una imagen global
} 
sublevación tomaría proporciones cada vez más amplias, convirtiéndose en un verdadero conflicto civil.

El 'caos' provocado por la insurrección estorbó por completo el centro neurálgico de cada ciudad, siendo la actividad de los Ayuntamientos inmediatamente paralizada. En Valladolid el mismo registro de plenos del ayuntamiento nos da un claro testimonio de esta situación, quedando 'blancas' las páginas que van desde el 18 de julio hasta el 31 del mismo mes7. No obstante, las escasas publicaciones que han tratado este tema nos indican como la represión y los fusilamientos fueron dramáticamente intensos durante aquella quincena asimismo como a lo largo de todo el verano de $1936^{8}$.

Con el fin de la guerra en abril de 1939, el Nuevo Estado - oficialmente reconocido y apoyado por el Eje - empezó su labor de consolidación. El primer objetivo se centró en la inclusión (administrativa, policial y represiva) de aquellas zonas que hasta el último momento habían permanecido bajo control republicano (el Levante y parte de Castilla la Nueva con Madrid). Una tarea no demasiado complicada, si se tiene en consideración que en el bando sublevado las experimentaciones administrativas ya habían empezado en otoño de 1936. Como en el caso de Valladolid, las capitales que

de la situación en toda España, más allá de los rumores, desmentidos oficiales y noticias confusas. [...] El día 18 el Gobierno Civil sería un continuo ir y venir de personas, intentándose [...] algunos arrestos de civiles identificados con la derecha ideológicamente más opuesta a la República». Durante todo el día se produjeron los combates callejeros que llevaron a la definitiva toma del Ayuntamiento, además de las principales instalaciones públicas; así como apareció en El Norte de Castilla del día 19 de julio de 1936, se pronunció por un comunicado de Radio Valladolid: «La guardia de Asalto se ha posesionado de esta emisión. Todo Valladolid es nuestro. No tardaremos dos días en lograr el triunfo. Nadie haga caso al Gobierno faccioso de Casares Quiroga. Todo el país de orden ha salido a la calle para combatir al criminal marxismo internacional». En los días siguientes el orden habría vuelto a la ciudad, siendo proclamada como una de las capitales del Alzamiento. MARTíN JIMÉNEZ, Ignacio, La Guerra Civil en Valladolid (1936-1939), cit, pp. 48-68.

7 La gravedad de la sublevación en Valladolid (mayor que en las otras capitales de Castilla la Vieja) fue evidente a la hora de considerar la situación entre la población: «en las calles vallisoletanas, luchaban encarnizadamente falangistas, guardias civiles, guardias de asalto y algunos paisanos contra grupos de obreros, principalmente ferroviarios. [...]. La sublevación de Valladolid fue lograda con mucho derramamiento de sangre, continuado después a lo largo de la guerra por frecuentes fusilamientos. En cambio, Segovia, Salamanca y Ávila, fueron conquistadas por los sublevados sin pérdida de vidas humanas». LÓPEZ CASTELLÓN, Enrique (coord.), Historia de Castilla y León, Tomo IX, Bilbao, Reno, 1986, pp. 203-204.

8 Recordamos los casos de las 478 personas encarceladas por ser afiliadas a la Casa del Pueblo de Valladolid, o el fusilamiento de significados líderes políticos como Landrove López, Juan Lozano Ruiz o José Maestro San José. MARTíN JIMÉNEZ, Ignacio, La posguerra en Valladolid (1939-1950). La vida en gris, Valladolid, Ámbito, 2002, p. 24. Posteriormente (en febrero de 1937) será descubierto el escondite del último e ilustre alcalde republicano, Antonio García Quintana, condenado a muerte por un Consejo de Guerra y ejecutado el 8 de octubre. En CARASA SOTO, Pedro (et. al.), Diccionario Biográfico de Alcaldes de Valladolid (1810-2010), Ayuntamiento de Valladolid, 2010, pp. 374375.Véase también PALOMARES IBÁÑEZ, Jesús María, La guerra civil en la ciudad de Valladolid: entusiasmo y represión en la "capital del alzamiento", Valladolid, ed. Ayuntamiento, 2001; y el documental recientemente estrenado: Todos los nombres: la represión franquista en Valladolid, ARMH (Asociación para la recuperación de la memoria histórica), Fenicia Creaciones, duración: 54 $\min [2009]$. 
habían quedado durante todo el conflicto bajo el control nacional ya funcionaban como ‘ejemplo organizativo' (en las instituciones y cuadros directivos locales) para el nuevo régimen 9.

En la capital castellana, desde 1937, había empezado a trabajar la nueva Comisión Gestora que se había reanudado bajo el 'alcalde-militar'ı Florentino Criado Sáenz. Desde su nombramiento, «su labor como Primer Regidor se encontró mediatizada por el contexto bélico en la que se desarrolló, un ambiente dominado por el miedo, la represión, la venganza y la depuración ${ }^{11}$. Es evidente que la principal tarea de esta primera Comisión fue por lo tanto la de concentrarse en labores de «apoyo a las tropas nacionales, con la organización de numerosas [...] suscripciones "voluntarias" destinadas a captar la "solidaridad" de los vallisoletanos»12. Esta descripción refleja perfectamente la situación a la que tuvo que hacer frente la población civil, siendo partidaria o no de los sublevados. Tal situación se prolongaría hasta mayo de 1937, cuando Criado Sáenz dejó la alcaldía en manos de otra importante figura del mando militar: Luis Funoll y Mauro. Bajo su mandato se desarrollaría una nueva fase de control, garantizando además - y es necesario precisarlo - la continuidad de la efímera maquinaría represiva. En un primer momento los cambios serían muy pocos y la atención del Ayuntamiento respecto a la sociedad urbana muy escasa. Sin embargo, y tras los primeros meses, la ciudadanía pudo contar con un alcalde más pendiente de las necesidades de una población afectada por el hambre (véase las ayudas financieras al Auxilio Social ${ }^{13}$ ) y un poco menos a las exigencias de los mandos militares.

\footnotetext{
9 El control de las Diputaciones y de las alcaldías se tomó a través la imposición, manu militari, de las respectivas comisiones. El desarrollo político se basaba con el uso de una estrategia «concebida en los años 1934-1936 [para] lograr un restablecimiento de la situación anterior a la crisis [de 1917]». Lo que habría sido en seguida el "modelo franquista", se podía considerar como un adelanto de un futuro «fascismo rural, sin grandes preocupaciones de rentabilidad por la unidad de producción - y, por consiguiente, de inversión-, fuerza de trabajo barata y mercado reducido. Ése era también el modelo falangista que le procede, el del Bloque Nacional de Calvo Sotelo, el del cartel de la gran patronal Unión Económica Española y, sin ser un proyecto netamente fascista sino con el matiz de una especial hegemonía católica, también de la CEDA». TUÑóN DE LARA, Manuel (et. al.), Historia de España, Valladolid, Ámbito, 1999, p. 619.

10 Hemos querido respectar los términos originales utilizados en las actas del pleno, por lo que el regidor del mismo es nombrado como "alcalde-militar".

11 CARASA SOTO, Pedro (et. al.), Diccionario Biográfico de Alcaldes de Valladolid, cit, p. 327.

12 Ibidem.

13 Se recomienda la lectura de ORDUÑA PRADA, Monica, El Auxilio Social (1936-1940). La etapa fundacional y los primeros años, Madrid, Escuela Libre, 1996.
} 


\section{La tranquilidad de la retaguardia y la aparente perfección del nuevo régimen}

En enero de 1938 el Ayuntamiento de Valladolid comenzaba su primera sesión plenaria tras un año dedicado a la organización de su Comisión Gestora. Desde sus asientos, los concejales manifestaban el júbilo por los victoriosos avances nacionales que en este mes culminaron con la toma de Teruel. En aquella época la ciudad castellana se había convertido oficialmente en una de las "capitales del Alzamiento", donde el control de la vida y del orden público estaban ya eficazmente vigilados por los militares y agrupaciones fieles al Movimiento. Desde la reanudación de las sesiones de la nueva Comisión en julio de 1936 no se habían producido muchos cambios ${ }^{14}$, excluyendo la proclamación del nuevo alcalde Luis Funoll. Los gestores seguían siendo prácticamente los mismos ${ }^{15}$. El gran entusiasmo con el que se vivían los delicados momentos de la contienda, tal y como se manifestó con la toma de Teruel, eran muy frecuentes siendo a menudo dedicados los primeros minutos de cada sesión a la exaltación de las operaciones militares, que seguían hacia la costa del Levante ${ }^{16}$.

Cada sesión se dividía en asuntos y propuestas que los gestores discutían de forma directa reduciendo así de forma considerable los debates. Las decisiones solían ser unánimes, siendo muy raras las discusiones entre los representantes de la Casa

14 La lectura de las primeras actas tras el Alzamiento, nos indica como la comisión vallisoletana se caracterizaba por ser estructurada de forma corporativa: «las instituciones locales, por tanto, reflejan en los primeros momentos una composición de carácter corporativo, dando entrada a los sectores más conservadores e influyentes de la localidad, aunque, en líneas generales, las grandes familias tradicionales no tendrán presencia directa». Tanto esta primera comisión como las que seguirán sus pasos, tendrán un cierto carácter falangista, siendo además núcleos para «el protagonismo de FE de las JONS [y] la paulatina incorporación de afiliados a la organización»; sin embargo su mayoría estará compuesta por antiguos afiliados a la CEDA o a la Unión Patriótica del periodo primorriverista o protagonizada por personas de cierta importancia en el ámbito económico-social. En GARCÍA COLMENARES, Pablo (et. al.), Historia y memoria de la Guerra Civil y primer franquismo en Castilla y León, Valladolid, Secretario de Publicaciones e Intercambio Editorial de la Universidad, 2007, p. 92.

15 En la primera sesión de enero de 1938, el listado de los componentes de la comisión se mantiene igual a la oficial del 31/07/1936, siendo compuesta por: gestor presidente Lorenzo Torremocha; gestores Juan Bautista Fernández Sanjuán, Ángel Salamanca, Gonzalo García Ganges, Antonio Castrillo, Saturnino Gutiérrez, Emilio Segoviano y Gregorio Hernández; secretario Rufino Zaragoza; interventor Manuel López Andrés; oficial mayor Burgos. Cfr., Archivo Municipal de Valladolid (desde ahora AMVA), Libro de plenos, no 226, 31/07/1936. Como dicho, desde mayo de 1937 fue nombrado alcalde el militar africanista de origen gallego, Luis Funoll y Mauro.

16 El 25 de febrero de 1938 se leyó delante de la Comisión el telegrama que confirmaba la segunda (y definitiva) toma de Teruel, el 6 de abril se celebró la «conquista y liberación» de Lérida, el 17 de junio la de Castellón de la Plana y, finalmente, el 27 de enero de 1939 la sesión desbordó en festejos (con los frecuentes gritos de "iArriba España!") a causa de la toma de Barcelona por los nacionales; AMVA, Libro de plenos, no 227. 
Consistorial. Esta sencilla maquinaria política se manifestaba de forma transparente a la hora de discutir los expedientes de aquellas personas que de alguna forma tenían aún ciertos enlaces con ideas, pensamientos o fórmulas políticas opuestas al régimen establecido por los golpistas. No era por lo tanto difícil que en casi todas las reuniones del pleno se discutiese un par de casos despectivamente calificados como 'rojos' o 'agitadores sociales' y en muchos casos denunciados por su presunta afinidad con la Casa del Pueblo. Poco a poco todos aquellos que habían sido investigados por una «conducta político-social francamente izquierdista» eran víctimas de semejante calificación $^{17}$.

Como hemos señalado con anterioridad, la práctica de la represión no era algo desconocido. Con la consolidación de los nuevos cargos, los primeros en desaparecer fueron «casi todos los socialistas que ocuparon cargos municipales entre 1931 y 1936 [...]. Igual suerte correrán numerosos sindicalistas, siendo especialmente castigado el activo foco de resistencia de los obreros ferroviarios ${ }^{18}$. A más de un año de distancia del levantamiento militar, la mayoría de los presos político-sindicalistas habían sido depurados; es decir fusilados o encarcelados. La política del Ayuntamiento vallisoletano respetó a la perfección las imposiciones gubernamentales sobre todo en el caso de la enseñanza: el pretexto era la erradicación del "peligroso germen socialista" todavía presente en algunas aulas, reemplazándolo con el estudio y la práctica de los valores nacionales, bajo la supervisión de una educación católica ${ }^{19}$. Analizando el libro de actas, - ya lo hemos dicho - la conducta de los gestores solía ser unánime: era práctica común resolver los expedientes en un plazo de tiempo muy reducido. Esta actitud nos demuestra que la atención del pleno comunal privilegiaba otros aspectos, ya que la depuración era considerada como un 'simple trámite' necesario para restablecer el

17 AMVA, no 227, 6/05/1938; durante esta etapa el Ayuntamiento examina de forma particular aquellos expedientes relacionados con la enseñanza, siendo destituida o suspendida la casi totalidad de los maestros y profesores inculpados. Un ejemplo de depuración en la enseñanza vallisoletana fue el caso del maestro Miguel Gamazo: «<grupo escolar "Miguel Iscar", sustitución maestra>. El maestro municipal Don Miguel Gamazo del Barro está suspendido del empleo y sueldo por 2 años. [...] Queda la substituta nacional». AMVA, Libro de plenos, no 227, 21/01/1938. Como advierte Paul Preston, «se practicó el terror contra grupos sociales específicos, ideológicamente definidos. El objetivo consistía en sistematizar e institucionalizar la represión y dirigirla (...). La represión política sistematizada y mecánica contribuyó de manera decisiva a asegurar el poder al "Nuevo Estado" franquista». En PRESTON, Paul, (et. al.), La República asediada. Hostilidad internacional y conflictos internos durante la Guerra Civil, Barcelona, Península, 1999, p. 237.

18 MARTÍN JIMÉNEZ, Ignacio, La Guerra Civil en Valladolid (1936-1939), cit, p. 208.

19 Sobre la depuración del profesorado español véase: NEGRÍN FAJARDO, Olegario, «Los expedientes de depuración de los profesores de instituto de segunda enseñanza resueltos por el Ministerio de Educación Nacional (1937-1943)», en Hispania Nova. Revista de Historia Contemporánea, ํㅜ 7, 2007,

URL: http://hispanianova.rediris.es/7/dossier/07d017.pdf [visitado el 14/03/2011]. 
orden y alejar los elementos "no deseados" de la cotidianeidad de la vida civil ${ }^{20}$. Resulta sorprendente observar como entre un expediente y el otro, tomó cierta importancia el debate sobre cuestiones urbanas como en el caso de las infraestructuras. Valladolid había sufrido algunos daños relevantes durante las breves pero intensas luchas callejeras, siendo ahora los bombardeos republicanos la única verdadera amenaza para la ciudadanía. Por esta razón, el Ayuntamiento enfocó su atención hacia una nueva fase de industrialización y urbanización para modelar la ciudad frente al riesgo de nuevos destrozos $^{21}$. Tales medidas se interpretaban como el impulso necesario para «buscar soluciones a fin de que, en un plazo no muy lejano, puedan ser realidades los deseos de ver instaladas en Valladolid industrias que sean en el porvenir la creación positiva de riqueza, de la que tan necesitada está nuestra querida Ciudad ${ }^{22}$. El empuje industrial fue una clara manifestación hacia la normalidad, pero esta vez bajo el lema del nacionalsindicalismo. Valladolid y su pleno tomaban seriamente en consideración la idea de convertirse en un impecable ejemplo de "ciudad nacional". El Ayuntamiento animó las sesiones con debates, propuestas y proyectos, para la organización de futuras obras tanto de utilidad pública como de embellecimiento urbano. Entre ellas no tardó en cobrar atención la cuestión de la edificación de monumentos en memoria de los 'caídos de la Cruzada', como demuestra la propuesta del gestor Saturnino Gutiérrez:

«El Sr. Gutiérrez dice que el "Diario Regional”, en su número de hoy, recuerda a todos los vallisoletanos, muy especialmente al Ayuntamiento, la hazaña realizada por los hijos de Valladolid, que, alternando estudiantes y obreros, empuñaron las armas contra las hordas marxistas en el Alto del León, en una lucha desigual, y lo hicieron así merced, principalmente, al germen depositado por el Caudillo Onésimo

20 No tenemos que olvidar que la mayoría de los depurados acabaría pasando por la maquinaria de la represión, siendo el mismo ayuntamiento implicado en ella. La historiadora López Gallegos afirma como las preocupaciones de la Comisión Gestora fueron igualmente atentas a «las destrucciones provocadas por la Guerra Civil de infraestructuras y el efecto negativo que ejerció en la economía local". Era evidente que "la recuperación [...] va a ser un proceso lento, que estará marcado por la escasez de materias primas, la deficiencia en el suministro eléctrico y del agua, y por la destrucción de las redes comerciales e infraestructuras». Cfr., LÓPEZ GALLEGOS, María Silvia, La vita cotidiana en la provincia de Valladolid durante la Guerra Civil, Valladolid, ed. Universidad de Valladolid 2006,

URL: < http://www.secc.es/media/docs/13_4_LOPEZ_GALLEGOS.pdf > [visitado el 4/02/2011], p. 19.

21 La magnitud con la que se miraba al futuro de la ciudad, se expresaba de esa forma: «a este asunto debe dedicarse la mayor atención posible, pues puede representar intereses de tal naturaleza para la vida y el desarrollo de la Ciudad, en su aspecto industrial [...], en cumplimiento de deberes tan primordiales como son el fomentar los intereses no sólo morales, sino los materiales que afectan a la vida municipal, sobre todo en los momentos actuales». (Discurso para la subasta del terreno denominado «Pradillo de S. Sebastián») AMVA, Libro de plenos, no 227, 18/01/1938.

22 Ibidem. 
Redondo con la creación de las Juntas de Ofensiva Nacional-Sindicalista desde el año 31, que supieron frenar las actuaciones socialistas. El Ayuntamiento [...], tomó, en sesión de 12 de agosto de 1.936, el acuerdo de erigir en aquel lugar una capilla y un monumento, y colocar en la escalera principal de la Casa Consistorial una alegoría y dos lápidas con los nombres de todos los caídos. Este acuerdo no podrá ser efectuado hasta que termine la guerra, para que ningún vallisoletano caído deje de figurar en ellas» ${ }^{23}$.

No obstante el afán del pleno, muchos de los monumentos en proyecto acabarían siendo retrasados (como es el caso del monumento a Onésimo Redondo en el cerro de S. Cristóbal, realizado en 1961) para favorecer otras obras consideradas más urgentes ${ }^{24}$. Según los planes, el monumento a los caídos del Alto del León (Sierra de Guadarrama) se celebraría como una obra digna del régimen, con la específica intención de rendir homenaje a «los que habían prestado su servicio o se habían sacrificado por el bando nacional». Más tarde se inauguró también otro monumento dedicado a la memoria del general Emilio Mola25, además de pedir la movilización de la población local para celebrar la amistad italo-española representada por el nutrido grupo de legionarios italianos establecidos en Valladolid ${ }^{26}$. No faltó tampoco la investidura del general Saliquet como "ciudadano honorifico", con ocasión de una de sus visitas a la ciudad ${ }^{27}$. Finalmente la inauguración del monumento a los caídos del Alto del León hizo que éste se convirtiese en un lugar de peregrinación ${ }^{28}$, alimentando el recuerdo y la plasmación

23 Discurso pronunciado por el gestor Saturnino Gutiérrez, en AMVA, Libro de plenos, no 227, 18/01/1938.

24 Una vez más, sería la prensa en atacar el Ayuntamiento, recibiendo por el contrario la crítica de algunos concejales más próximos a la pragmática falangista: «en una palabra, hay que ser ciudadanos disciplinados. [...] Al hacer estas manifestaciones cree [el pleno] interpretar el sentir de los compañeros de la Comisión Gestora, en especial del Sr. Alcalde ausente, para que se sepa que los vallisoletanos, en lugar de imprimir proyectos o iniciativas en la Prensa, o dar gusto al dedo o a la pluma, deben venir a exponerlos a las autoridades, representadas por quién sea, que les acogerán con mucho cariño [...]. No ha terminado la gloriosa gesta [la guerra] y cuando llegue el momento el Ayuntamiento será el primero en conmemorar como se merecen a los hijos de Valladolid y de Castilla, que pusieron tan alto el nombre de Valladolid y de Castilla en el Alto de los Leones». AMVA, Libro de plenos, ํㅡ 227, 18/02/1938.

25 AMVA, Libro de plenos, no 227, 27/05/1938.

26 A finales de mayo de 1938 una delegación capitaneada por el general Rivolta, visitó la alcaldía recibiendo los agradecimientos y el apoyo de la comisión municipal por el trabajo prestado por la Italia fascista a la España de Franco. AMVA, Libro de plenos, no 227, 1/06/1938.

27 El general, que había sido uno de los primeros jefes del mando militar sublevado en Valladolid, pronunció en aquella ocasión un largo discurso que tuvo come objeto de atención el «cariñoso recuerdo a Onésimo Redondo y a Enrique Estefanía, víctimas del deber al servicio de España». AMVA, Libro de plenos, no 227, 17/06/1938.

28 Además del monumento a los caídos, desde el «12 de agosto de 1.936 [...] se acordó realizar en tiempo oportuno varios homenajes a las juventudes vallisoletanas defensoras de España, y en 
del mito de Onésimo Redondo. Entre la opinión pública el 'Caudillo de Castilla' no era sólo uno de los iconos de la liberación de España, sino que también personificaba la redención y el sacrificio por la causa falangista. Paradójicamente "el mito" carecía de un digno lugar donde descansar, razón por la cual los elementos más destacados del falangismo local se pronunciaron para implicar toda la ciudadanía a colaborar en el proceso de mitificación del propio Redondo. «No se dan cuenta los vallisoletanos de que, gracias a las campañas y predicaciones de Onésimo Redondo, había cinco mil hombres preparados para la lucha en Valladolid»; y concluía el portavoz falangista Gutiérrez: «es necesario que el Ayuntamiento haga saber al pueblo de Valladolid que Onésimo Redondo fue el verdadero Caudillo del Movimiento Nacional en Valladolid» ${ }^{29}$.

\section{Entre doctrina y vida cotidiana: Valladolid, un 'experimento falangista'}

Ciudades de la retaguardia como Valladolid sufrieron muy por encima los horrores materiales de la guerra, siendo otros los problemas que afectaron con más preocupación a su población. Una de las mayores dificultades que agravaron el peso del conflicto fue sin duda el hambre. Una parte considerable de la población había sufrido la pérdida de algún familiar (tanto entre los que enviaron hijos y maridos al frente como aquellos que los perdieron en alguna sumaria ejecución en los campos cercanos al núcleo urbano), teniendo que hacer frente a la difícil situación de falta de trabajo y niños que alimentar. No obstante las promesas nacionales, durante la guerra y en los años sucesivos «comer cada día constituía un reto permanente. Y hasta una obsesión, que llevaba a procurar por todos los medios la acumulación de alimentos»30. Es probable que esta parte de la población empezase a sentirse "cansada por la guerra" 31 , aunque por otro lado no faltaron quienes seguían manteniendo un cierto estatus económico y social que no les alejó de un alto tenor de vida: «la buena sociedad, en cambio, se refugiaba en sociedades recreativas exclusivas, como el Círculo de Recreo, o restaurantes como Yago, siendo una costumbre de nuevo cuño los picnics al Pinar de Antequera, o los raids automovilísticos por la provincia»32. Lo que nunca faltó en la

especial a los que combatieron y sucumbieron en el Alto del León». AMVA, Libro de plenos, nº 227, $11 / 03 / 1938$.

29 AMVA, Libro de plenos, no 227, 17/07/1938. Discurso del gestor Saturnino Gutiérrez.

30 MARTÍN JIMÉNEZ, Ignacio, La posguerra en Valladolid (1939-1950), cit., p. 244.

31 ABELLA, Rafael, La vida cotidiana durante la guerra civil. La España nacional, Barcelona, Planeta, 2004, p. 237.

32 MARTÍN JIMÉNEZ, Ignacio, La posguerra en Valladolid (1939-1950), cit., p. 250. 
retaguardia fue el persistir de un control sistemático de los comportamientos de la población; la "nacionalsindicalización" de la sociedad requería la imposición de «un estilo de vida muy determinado», en el que la familia desempeñaba un papel central en las relaciones interpersonales33. Entre los partidarios del adoctrinamiento popular basado en los puntos de Falange se distinguió el ya citado concejal Saturnino Gutiérrez Castillo34.

Un atento análisis de los registros nos demuestra que Gutiérrez encabezó, desde la creación de la Comisión en el julio del 1936, todo tipo de intervenciones en defensa de la doctrina joseantoniana, razón por la cual se puede perfectamente calificar la actitud de este regidor como la de un perfecto falangista 35 . Saturnino Gutiérrez actuaba con la voluntad de crear una comisión que manifestara públicamente su apoyo a la causa nacional, sobre todo a la hora de recordar a las víctimas falangistas vallisoletanas caídas en el frente. Sin embargo, la máxima autoridad del Ayuntamiento, el alcalde Funoll, se manifestaba de forma más ambigua. Según el estudio de Guillermo Revilla, el regidor mantuvo durante todo su mandato una difícil relación con los cargos que Falange controlaba, favoreciendo por tanto el apoyo de José Porres y Porres (Gobernador provincial y falangista) con el conjunto más radical del pleno comunal ${ }^{6}$. El falangismo

33 Ibidem, p. 289.

34 Los pocos datos que tenemos de Saturnino Gutiérrez se refieren a su inscripción en el censo electoral de la provincia de Valladolid, datado a marzo de 1930. En el listado de nombres del «distrito municipal n.1, PLAZA» (perteneciente a la Parroquia de San Lorenzo), aparece: Saturnino Gutiérrez Castillo, 31 años, dependiente, domiciliado en la calle Sanchéz Roman no 6. (Cfr. Servicio General de Estadística, Renovación total del censo electoral de la capital, Imprenta Provincial, Valladolid, 1930, p. 33). Sin embargo ha sido de relevante dificultad apurar uno de los apellidos del gestor Gutiérrez por la inscripción en dicho censo de un homónimo de la misma edad, Saturnino Gutiérrez Rodríguez de profesión obrero. Para resolver el enigma, nos ha sido de ayuda una investigación de María S. López Gallegos (véase en la siguiente nota), donde se nombra el Sr. Gutiérrez Castillo como perteneciente del directivo de la CONS (Central Obrera NacionalSindicalista). El gestor Gutiérrez fue proclamado concejal en la primera sesión municipal tras el Alzamiento (31/07/1936) y lo mantuvo hasta el 1/12/1939. AMVA, Libro de plenos, no 228, 20/01/1939.

35 Según la descripción de López Gallegos, el concejal Gutiérrez fue un miembro destacado de la CONS, bajo la dirección del líder sindical e intimo amigo de Onésimo, Emilio Gutiérrez Palma. La CONS destacó durante la etapa republicana por su actitud "revolucionaria", planteándose como «alternativa totalmente al margen del sistema ya que proclaman como objetivo acabar con éste». No es por lo tanto difícil entender la postura de Saturnino Gutiérrez durante la sucesiva etapa consistorial, siendo él mismo el resultado de aquella «actitud cada vez más agresiva y activa por parte de la CONS» experimentada durante el periodo entre 1934 y 1936. Al terminar la guerra civil, «los miembros más representativos de la CONS [...], serían Sérvulo Martín Rodríguez (Delegado Provincial), Saturnino Gutiérrez Castillo (Secretario Provincial) y como Delegado Local cuenta con Modesto Diez». En LÓPEZ GALLEGOS, María Silvia, La lucha por el control sindical en Valladolid: el enfrentamiento entre católicos, tradicionalistas y falangistas (1936-1938), Valladolid, ed. Universidad de Valladolid,

URL: <http://dialnet.unirioja.es/servlet/articulo?codigo=1036706> [visitado el 23/02/2011], pp. 562-567.

36 CARASA SOTO, Pedro (et. al.), Diccionario Biográfico de Alcaldes de Valladolid, cit, pp. 367-368. 
en Valladolid estaba lentamente haciéndose con el control municipal disimulando un enfrentamiento con los propios mandos militares37. Gutiérrez, respaldado por el Gobernador Civil, dominaba las sesiones y en cada una de ellas intervenía defendiendo la justificación de financiaciones finalizadas a Falange. Suyas fueron las propuestas de contribuir al coste de los campamentos de verano de la Organización Juvenil de Falange, obteniendo una vez más el apoyo común: «el Sr. Gutiérrez dice que, después de las manifestaciones de los Sr. Segoviano [concejal] y del Alcalde Presidente, no le queda más que dar las gracias en nombre de los muchachos que irán a la expedición nacional-sindicalista y futuros héroes de la Patria, que harán que el impero español sea una realidad $»^{8}$. De igual manera pidió que fuese celebrado un homenaje al fundador de Falange Española, José Antonio Primo de Rivera, tras oficializarse su muerte39.

Mientras la guerra seguía con sus batallas y con los avances de las tropas nacionales, la mayor preocupación de la retaguardia se convirtió en la completa eliminación de posibles rastros izquierdistas o de oposición al régimen. Como hemos dicho anteriormente, la represión «tenía objetivos definidos sobre los partidos y sindicatos de clase [...]. Se hizo una profunda "limpieza" ideológica con los profesionales e intelectuales, sobre todo los enseñantes, y miembros de profesiones liberales»40. En el mismo Ayuntamiento se produjeron frecuentes debates sobre algunos expedientes presentados, siendo ocasionalmente los mismos trabajadores municipales las víctimas de denuncias o difamaciones ${ }^{41}$. Como ha escrito Rafael Abella: «los criterios represivos fueron estrictos, duros, para asegurar una retaguardia incierta en una coyuntura a vida o muerte [...]. A medida que la guerra se plasmaba en contienda más delimitada, la represión se mantendría, aunque atenuada, como

37 Como observa el historiador Palomares Ibáñez, en el Ayuntamiento de Valladolid se hizo tangible un gradual traspaso de los poderes desde el militar hacia el falangista; «el desembarco falangista rebasó el perímetro partidario que pudieran ejercer sus socios en los mandos y servicios de la organización. Su militancia dejó huellas en las instituciones que participaron, [...] era un derecho adquirido en la pasada contienda». PALOMARES IBÁÑEZ, Jesús María, El primer franquismo en Valladolid, Valladolid, Secretariado de Publicaciones e Intercambio Editorial de la Universidad, 2002, p. 93.

38 AMVA, Libro de plenos, no 227, 29/07/1938.

39 Gutiérrez marcó con su intervención la memoria del antiguo Jefe de Falange: «esta sesión ha comenzado con la expresión del sentimiento de la Corporación por la muerte del gran profeta José Antonio Primo de Rivera, y debe terminar con un homenaje a la memoria de este Caudillo que con su juventud y ejemplo hizo posible el Movimiento de salvación de tanta importancia a que se lanzó España, a la que tanto amó. Para ello pide que todos los presentes contesten a las consignas de ¡España! ¡España! ¡España!; ¡José Antonio Primo de Rivera! ¡José Antonio Primo de Rivera! ¡José Antonio Primo de Rivera!; ¡Viva el Generalísimo!; ¡Arriba España!». AMVA, Libro de plenos, no 227, 7/10/1938.

40 GARCÍA COLMENARES, Pablo (et. al.), Historia y memoria de la Guerra Civil y primer franquismo en Castilla y León, cit, pp. 49-50.

41 Queda disponible a la lectura una larga sesión del pleno dedicada a este asunto en: AMVA, Libro

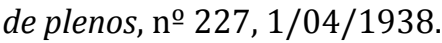


muestra de que el nuevo orden no ablandaba sus caracteres de dureza»42. El objetivo primario y fundamental no cambiaría durante toda la durada del conflicto: aniquilar cualquier residuo - por lo menos en la 'ejemplar' Valladolid - del régimen republicano ${ }^{43}$.

\section{El fracaso de la 'revolución' y el porvenir en la España nacional}

La larga batalla finalizada con la ocupación de Barcelona y buena parte de Cataluña en enero de 1939, provocó en Valladolid una oleada de manifestaciones destinadas a celebrar la importante victoria nacional44. Parecía inevitable la rápida conclusión del conflicto y en la ciudad castellana tanto la población civil como las autoridades locales, tenían ahora una confianza absoluta en la victoria final. La Casa Consistorial lucía desde hace tiempo un nuevo panel con el 'yugo y las flechas'45 - eterno símbolo de falange - a la sombra del cual empezó a discutirse el plan de normalización de la vida cotidiana frente al inminente final de la guerra. Hacía tiempo que la filosofía del nuevo régimen, especialmente aquí en la retaguardia, venía siendo la difusión entre los ciudadanos de un "nuevo espíritu”, basado en aquella corriente que había favorecido el desarrollo de una revolución nacionalsindicalista. Finalizada la cruzada que la España nacional había elevado contra la barbarie roja, empezaba la fase proselitista que Falange aspiraba ahora a dirigir. Su principal desafío seguía siendo la implantación de un "régimen de masas" nacional y patriótico, de carácter corporativista, defensor del derecho al trabajo y promotor de valores morales conformes al pensamiento joseantoniano; en dos palabras, el Estado Nacionalsindicalista.

42 ABELLA, Rafael, La vida cotidiana durante la guerra civil. La España nacional, cit, pp. 62-63.

43 A diferencia que en el entorno rural (véase: GARCíA COLMENARES, Pablo (et. al.), Historia y memoria de la Guerra Civil y primer franquismo en Castilla y León, cit, pp. 32-41), la represión en la ciudad se caracterizó por estar «bajo un férreo control, como bien indicaba la Ley de Prensa de 22 de abril de 1938. La Ley de Responsabilidades Políticas [9 febrero de 1939], continuó siendo para muchos un dogal, hasta tanto demostrasen su inocencia o abonasen las sanciones económicas impuestas a los condenados y a sus familiares o herederos». PALOMARES IBÁÑEZ Jesús María, El primer franquismo en Valladolid, cit, p. 106.

44 Durante el mes de enero las autoridades ciudadanas siguieron con atención las fases de avance hacia la ciudad condal; en el momento de su ocupación el pleno afirmaría como «no quiere que se levante esta sesión sin hacer constatar la profunda alegría y el vibrante entusiasmo que ha producido en el pueblo de Valladolid y en su Ayuntamiento la grandiosa victoria que ha obtenido nuestro glorioso Ejercito con la conquista de Barcelona [...]. Termina con los gritos de ¡Viva España!, ¡Viva el Ejército! [...], que es contestado por todos los presentes puestos en pie y con el brazo en actitud de saludo». AMVA, Libro de plenos, no 228, 27/01/1939.

45 En este caso aludimos a un hecho muy poco conocido y aclarado por el historiador Ibáñez: «debe recordarse el emplazamiento en la fechada consistorial del colosal emblema del Yugo y las Flechas mantenido allí por mucho tiempo». PALOMARES IBÁÑEZ, Jesús María, El primer franquismo en Valladolid, cit, p. 94. 


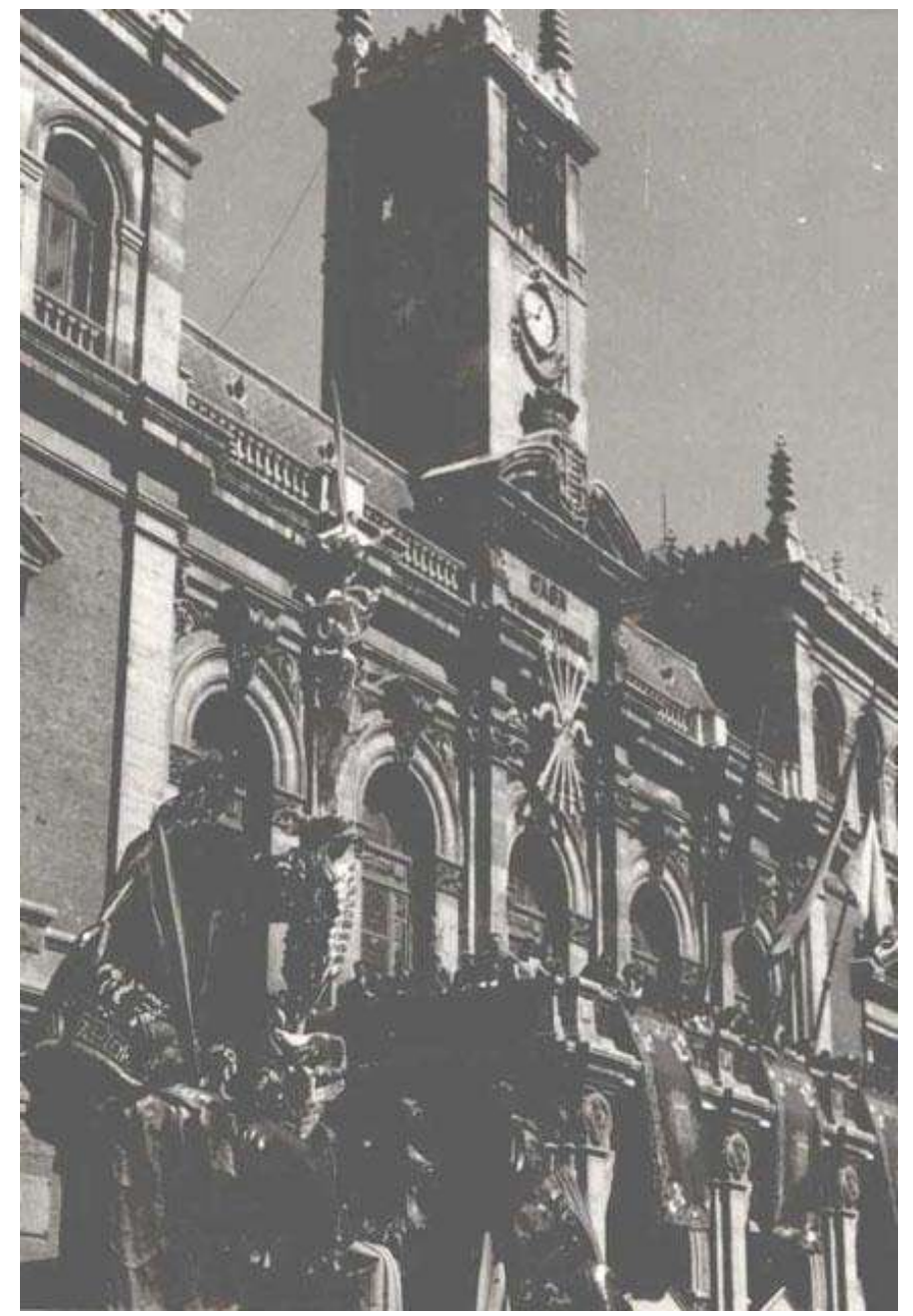

Fig. 1 Fechada del Ayuntamiento de Valladolid con los símbolos de Falange, durante la procesión del "Domingo de Ramos", primavera 1939. (Archivo-Fundación J. Díaz)46.

En la confusión de aquella hora, muy lejos del aparente estado de perfección anhelado al comienzo de la guerra, justicia y valores humanos se entremezclaban entre sí, tanto en el frente como entre la población de la retaguardia. Si por un lado se miraba hacia la nueva etapa que la España nacional se preparaba a vivir, por el otro el aparato represivo procuró dejar muy claro quienes tenían en sus manos el poder 47.

46 Archivo Fotográfico de la Fundación-Centro Etnográfico Joaquín Díaz, imagen: VA0537.

47 Como observa Jiménez, «el ejercicio del poder se va a aplicar de forma arbitraria. En ese contexto de confusión entre las recién instituidas estructuras de poder y la actuación de patrullas a título privado, surgirá con siniestra fuerza la figura del delator [...]. Numerosos espontáneos denunciantes anónimos se encontrarán dispuestos a presentar denuncias». Una situación que no dejaría de caracterizar los siguientes años de la posguerra: «por lo que tuvo que editarse un decreto impidiendo que simples testimonios incriminatorios bastasen para que personas [...] entraran en 
Durante los primeros meses del año, en el Ayuntamiento se trabajó asiduamente para resolver asuntos como el abastecimiento de agua, la apertura de zanjas y la limpieza de calles ${ }^{48}$; se planteó la construcción de una nueva guardería infantil luego ofrecida al Auxilio Social49 y volvió a considerarse el imponente 'plan Cort': "proyecto de ensanche y extensión de la ciudad, plano general de alineaciones del interior y Ordenanzas de urbanización» ${ }^{\circ}$. El control que ejercían las autoridades de Valladolid sobre sus ciudadanos demostró ser el reflejo del poder que Falange tenía sobre su feudo por antonomasia. Esta condición se consolidó aún más con el dominio de los medios de comunicación, que fueron la base del control social. Por ejemplo, en la plaza mayor vallisoletana se instaló un altavoz de la emisora FET n. 1, donde se daban «a conocer por el mismo las verdades del Movimiento Nacional sindicalista base del Nuevo Estado»51. También se aprobó la financiación de periódicos de propaganda nacional como Libertad, Diario Regional y Reinaré en España ${ }^{52}$.

Mientras las ofensivas nacionales presionaban prácticamente la totalidad de la costa mediterránea, el 17 de febrero llegó el telegrama que confirmó la definitiva ocupación de Cataluña y poco después, el 31 de marzo, se oficializaba la toma de Madrid. La guerra había terminado y la reacción de las autoridades locales dejó en evidencia la satisfacción por el éxito militar:

\footnotetext{
las redes de ese aparato burocratizado y arbitrario». MARTÍN JIMÉNEZ, Ignacio, La posguerra en Valladolid, cit, pp. 314-315.

48 AMVA, Libro de plenos, no 228, 13/01/1939.

49 Ibidem, 20/01/1939.

50 La aprobación del plan de urbanización presentado por el arquitecto Cort, dio vida a un amplio debate donde las autoridades tuvieron que enfrentarse a las numerosas críticas recibidas por los gastos y el derribo de numerosos edificios. A la aprobación del proyecto se afirmó: «merced al caciquismo y al favoritismo de los partidos políticos que imperaban antes, no se hacía nada en beneficio de Valladolid. Es ahora [...], cuando el vecindario se ha interesado por la labor del Ayuntamiento, y una de sus mayores satisfacciones es haber comprobado que antes, cuando los Ayuntamientos eran políticos, el pueblo de Valladolid veía con indiferencia la actuación municipal, $y$, en cambio, ahora el pueblo entero de Valladolid se ha preocupado por la gran obra que ha proyectado el Ayuntamiento». , Libro de plenos, no 228, 20/01/1939.

51 AMVA no 228, 13/10/1939, 306v, véase también el texto de PALOMARES IBÁÑEZ, Jesús María, El primer franquismo en Valladolid, cit, p. 94.

52 Los primeros dos pedían expresamente una suscripción del Ayuntamiento para hacer frente al «gran número de peticiones que de todas las unidades del frente recibe suplicando el envío de nuestro periódico" (AMVA, Libro de plenos, no 228, 17 y 24/02/1939). Es útil recordar que como «en el caso de Valladolid, la fuerte tradición falangista cuna de las JONS y de su fundador Onésimo Redondo, hacia que las repercusiones de cualquier acontecimiento, nueva legislación, o circunstancia internacional, se vivieran de manera especialmente intensa. [...] Sin embargo la propaganda ejercida por estos medios se caracterizó por su escaso poder persuasivo». Cfr., GÓMEZ CUESTA, Cristina, «Valladolid en la posguerra: del escenario falangista a la realidad social», en Investigaciones Históricas: Época moderna y contemporánea, no 21, Universidad de Valladolid, 2001, pp. 306-307.
} 
la Comisión Gestora queda enterada de los telegramas de felicitación que, con motivo de la victoriosa terminación de la guerra, el Sr. Alcalde-Presidente ha dirigido a S. E. el Generalísimo y Jefe del Estado [...]. El Sr. Presidente propone que, por ser esta la primera sesión que se celebra después de la declaración oficial de la victoriosa terminación de la guerra, se haga constatar en acta la satisfacción inmensa del Ayuntamiento y pueblo de Valladolid, así como su afecto, adhesión incondicional y gratitud al invicto Caudillo53.

Terminada la guerra, lo primero fue cumplir con las tareas que habían sido aplazadas. En primer lugar se aprobó la financiación necesaria para la construcción de la tumba de Onésimo Redondo; finalmente el Caudillo de Castilla podía «reposar en un panteón digno de la grandeza de su vida luchadora»54, mientras que las demás financiaciones estarían reservadas para los festejos de la Victoria. El Ayuntamiento decidió celebrar el acto no sólo con fiestas y manifestaciones públicas, sino también con la compra de textos de la 'Editora Nacional' sobre temas de doctrina que serían repartidos entre la población55.

Es cierto que la conclusión del conflicto generó entre las autoridades un enorme júbilo. Esto se comprobó en primer lugar con el envío de una innumerable cantidad de cartas y telegramas de felicitación hacia el Caudillo, seguidos por numerosos actos que celebraban el final de la contienda. Según las disposiciones del Gobierno central «se encomendó a este Ayuntamiento la organización de algunos festejos y actos, entre ellos la construcción de arcos triunfales, adorno de calles, una función de fuegos artificiales y reparto de cinco mil panes entre los pobres y de comidas en los Asilos de la capital ${ }^{6}$. Durante toda la primavera y buena parte del verano se sucedieron numerosas manifestaciones, como la despedida de los legionarios italianos (con acto solemne en la Casa Consistorial57), la organización de concursos, la celebración del tercer aniversario del Alzamiento y la donación a Valladolid de la «Cruz Laureada de San Fernando»58.

53 AMVA, Libro de plenos, nำ 228, 8/04/1939.

54 AMVA, Libro de plenos, no 228, 23 y 24/02/1939.

55 Se precisa la compra de «una obra del Excmo. Sr. Ministro de la Gobernación, titulada "Siete discursos", que acaba de publicarse, y de otras de José Antonio, Fernández Cuesta y Ruiz de Alda, que están en preparación, todas cuales resumen los postulados políticos y sociales que son nervios y raíz de nuestra histórica Revolución Nacional-Sindicalista»; cfr., AMVA, Libro de plenos, no 228, 24/02/1939.

56 AMVA, Libro de plenos, no 228, 26/05/1939.

57 Aparece en el libro de plenos una dedicatoria del general Rivolta, jefe del "Comando Centro Istruzioni"; AMVA, Libro de plenos, no 228, 14/07/1939.

58 La condecoración fue motivada por el mismo Franco según telegrama llegado al Ayuntamiento: «Valladolid, a lo largo de ocho años, supo sembrar inquietudes revolucionarias, no sólo dentro de su demarcación, sino irradiando a España entera modos y actitudes de combate. Culminó tan ejemplar conducta en la jornada del dieciocho de julio, en que la Capital castellana dio resonancia guerrera al 
Por el otro lado, ni siquiera las celebraciones de la victoria contribuyeron a disminuir la labor represiva. Mientras la comisión discutía sobre los festejos ${ }^{59}$, no faltaban nuevos casos de depuración, siendo los últimos imputados denunciados por provocar “actividades político-sociales” peligrosas por el nuevo régimen ${ }^{60}$.

Con la llegada del inverno de 1939 el Ayuntamiento se preparaba para el relevo de la Comisión gestora. Tras recordar los comienzos en medio del caos provocado por los primeros días del Alzamiento ${ }^{61}$, había llegado la hora de proceder «a la total renovación de la [Comisión] Gestora, en subordinación a la directriz política establecida para la organización administrativa de todos los órganos del Estado y correlativos, en esta nueva etapa de la reconstrucción nacional» ${ }^{62}$.

Durante poco más de tres años, las autoridades locales habían trabajado para conciliar el ejercicio del poder en la ciudad. No obstante, el alcalde no logró nunca evitar que se implantase una corriente político-administrativa de clara orientación falangista, siendo éstos respaldados además por su cercanía doctrinal con los aliados fascistas (en Valladolid se fundó una Casa del Fascio en marzo de 193863). Como afirma Jiménez, los primeros años del franquismo se vivieron con una «situación de descontento generalizado respecto al ejercicio de la autoridad municipal», ya que en el seno de Falange no sólo empezaban a pesar las divisiones internas, sino también las medidas gubernamentales que pretendían frenar el afán revolucionario de los camisas

primer eco azul de las Camisas falangistas y de los uniformes militares y de los presos de orden político, aplastando la insistencia del notable pero marxista que venía preponderando la ciudad. [...] Así dispongo por el presente decreto, dado en Burgos a diecisiete de julio de mil novecientas treinta y nueve.- Año triunfal de la Victoria.- Francisco Franco». AMVA, Libro de plenos, no 228 , 21/07/1939.

59 Entre otros asuntos, el ayuntamiento aprobó la financiación, con el respaldo de otras ciudades, de la "Espada de la Victoria"; regalo para el Caudillo con el fin de celebrar la Victoria y el fin de la guerra. AMVA, Libro de plenos, no 228, 15/09/1939.

60 Ejemplar puede ser el caso de Abraham Vela Cano, siendo acusado no sólo de afiliación comunista, sino también de ser un «colaborador de varias sociedades afectas a la Casa del Pueblo; que secundó cuantas huelgas se produjeron en esta capital y muy particularmente la del día 19 de junio de 1936; [...] el día 18 de julio de 1936 se negó a salir a extinguir los incendios provocados por las hordas marxistas en las iglesias del Carmen y de San Esteban de esta ciudad; que es elemento poco amante de la religión, habiendo tenido a sus hijos sin bautizar, a los que ya tenía afiliados a la agrupación juvenil de "pioneros", siendo desafecto a la causa nacional». AMVA, Libro de plenos, noㅡ 228, 1/09/1939.

61 Afirmaba el alcalde: «la misión más difícil de la Comisión Gestora que hoy cesa, fue la de llevar a cabo cuantos trabajos extraordinarios fueron necesarios en los primeros momentos de incertidumbre de la Guerra Nacional». AMVA, Libro de plenos, no 261, 1/12/1939.

62 Ibidem, (fragmento del discurso del Gobernador civil Jesús Rivero Meneses).

63 Véase el documento del Instituto Luce sobre la inauguración de la sede del Fascio Italiano en Valladolid: Istituto Luce - Cinegiornali, Spagna. Valladolid. Inaugurazione della nuova sede del Fascio Italiano. 23/03/1938, [video] Italia, 1938, 1'27",

URL:<http://www.archivioluce.com/archivio/jsp/schede/videoPlayer.jsp?tipologia=\&id=\&physDo $c=15605 \& d b=$ cinematograficoCINEGIORNALI\&findIt=false\&section=/>, [visitado el 29/03/2011]. 
azules ${ }^{64}$. Comenzaba una nueva etapa para la ciudad en la que todo quedaba por hacer. Por un lado se recuperaban lentamente orden y tranquilidad, mientras no se podía decir lo mismo respecto al establecimiento de los altos cargos que durante mucho tiempo protagonizarían una lucha para ocupar un lugar privilegiado dentro de las altas esferas del poder del nuevo régimen. Mucho perdió Falange en este juego, ya que en el seno de la administración la regularización de las instituciones alejó gradualmente a los defensores de la causa revolucionaria. El país empezaba a virar hacia un sistema distinto al que había imaginado Falange, quedando evidentes no sólo la pérdida de su posición preeminente dentro del nuevo Estado, sino también resultando incumplidos sus sueños revolucionarios. Sin embargo en Valladolid, al igual que en muchas otras ciudades, la arenga iba a ser la misma de siempre: la defensa de «la doctrina Nacional Sindicalista, que actualmente discuten muchos pero comprenden pocos y otros combaten» 65 .

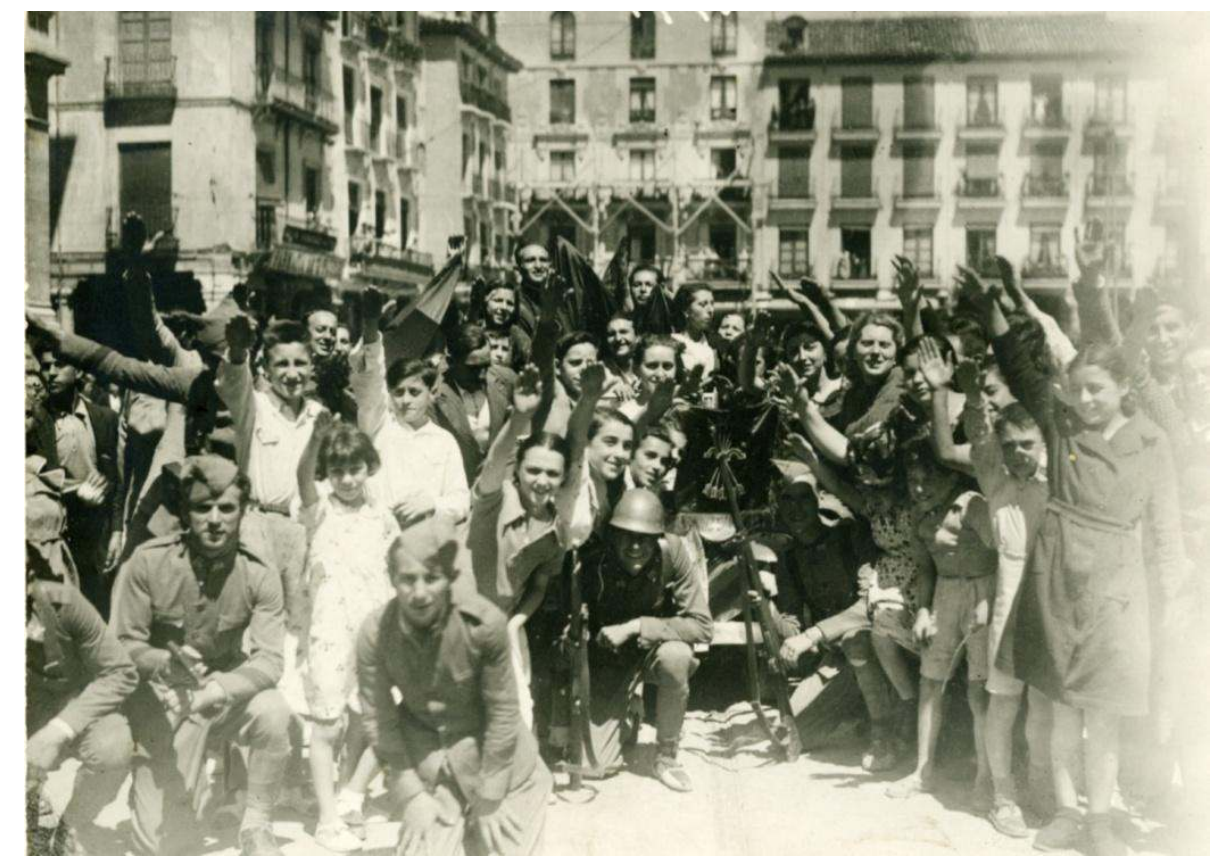

Fig. 2 Valladolid, abril de 1939 - Celebraciones por el final de la guerra civil en la plaza mayor de la ciudad (Archivo-Fundación J. Díaz) ${ }^{66}$.

64 MARTÍN JIMÉNEZ Ignacio, La posguerra en Valladolid (1939-1950), cit., pp. 324-328.

65 AMVA, Libro de plenos, no 228, 24/11/1939 (discurso de Saturnino Gutiérrez).

66 Archivo Fotográfico de la Fundación-Centro Etnográfico Joaquín Díaz, imagen: A1939_copia2. 


\section{* El autor}

Matteo Tomasoni, se ha licenciado en Historia Contemporánea en la Università di Bologna (2008) y desde 2009 es doctorando en la Universidad de Valladolid. Se ocupa de temas relacionados con la historia contemporánea de España, dedicándose especialmente al análisis de la Segunda República y de los movimientos pertenecientes a la extrema derecha española de los años Treinta: La conquista del Estado, JCAH, JONS y Falange Española. Colabora además en otros proyectos académicos y es miembro de la redacción de Diacronie.

URL: < http://www.studistorici.com/2008/o9/14/matteo-tomasoni/ >

\section{Per citare questo articolo:}

TOMASONI, Matteo, «Política y sociedad en la retaguardia nacional: Valladolid 'capital del Alzamiento' (19361939)», Diacronie. Studi di Storia Contemporanea: Spagna Anno Zero: la guerra come soluzione, 29/07/2011, URL:<http://www.studistorici.com/2011/07/29/tomasoni_numero_7/ >

\section{Diacronie Studi di Storia Contemporanea $\beta$ www.diacronie.it}

Risorsa digitale indipendente a carattere storiografico. Uscita trimestrale. redazione.diacronie@hotmail.it

Comitato di redazione: Marco Abram - Giampaolo Amodei - Jacopo Bassi - Luca Bufarale - Alessandro Cattunar - Alice De Rensis Barbara Galimberti - Deborah Paci - Fausto Pietrancosta - Martina Sanna - Matteo Tomasoni - Luca Zuccolo

Diritti: gli articoli di Diacronie. Studi di Storia Contemporanea sono pubblicati sotto licenza Creative Commons 2.5. Possono essere riprodotti a patto di non modificarne i contenuti e di non usarli per fini commerciali. La citazione di estratti è comunque sempre autorizzata, nei limiti previsti dalla legge. 